\title{
Evidence of Improved Small Airways Function after Azithromycin Treatment in Diffuse Panbronchiolitis
}

\author{
Shane Hanon Sylvia Verbanck Daniel Schuermans Bram Vanden Berghe \\ Eef Vanderhelst Walter Vincken
}

Respiratory Division, University Hospital UZ Brussel, Brussels, Belgium

\section{Established Facts}

- Diffuse panbronchiolitis is an inflammatory disease of the respiratory bronchioles treatable with macrolide antibiotics. Standard lung function testing is part of the baseline assessment and follow-up.

\section{Novel Insights}

- In addition to the standard lung function tests, we used a state-of-the-art analysis of the multiple breath nitrogen washout test to measure acinar and conductive ventilation heterogeneity.

- This allowed us to actually localize and measure the small airway abnormalities in diffuse panbronchiolitis and to demonstrate improvement of small airways function under macrolide antibiotic therapy.

\section{Key Words}

Small airways function $\cdot$ Acinar airways $\cdot$ Conductive airways $\cdot$ Multiple breath washout $\cdot$ Diffuse panbronchiolitis - Macrolides

\footnotetext{
Abstract

A 67-year-old never-smoker was diagnosed with diffuse panbronchiolitis (DPB) and was started on $250 \mathrm{mg}$ azithromycin twice weekly. Over a 16-month observation period, lung function was assessed monthly, including a dedicated small airways test, the multiple breath nitrogen washout (MBW) with indices $S_{\text {cond }}$ and $S_{\text {acin }}$ of ventilation heterogeneity at
}

the level of the conductive and acinar air spaces, respectively. Baseline measurements indicated moderate airway obstruction, air trapping and considerable dysfunction of the small airways around the acinar entrance. Treatment resulted in excellent symptomatic improvement paralleled by marked improvements in $\mathrm{FEV}_{1}, \mathrm{FVC}, \mathrm{RV} / \mathrm{TLC}, \mathrm{S}_{\text {cond }}$ and $\mathrm{S}_{\text {acini }}$; by contrast, there were no consistent changes in $\mathrm{FEF}_{75}$ or $\mathrm{TL}_{\mathrm{CO}}$. While improvements were such that $\mathrm{S}_{\text {cond }}$ fell within normal limits after 5 months, $S_{\text {acin }}$ remained abnormal even after 16 months of treatment. This suggests a distinct acinar structural abnormality in DPB that cannot be reversed by azithromycin.

Copyright $\odot 2012$ S. Karger AG, Base

\section{KARGER}

Fax +4161306 1234

E-Mail karger@karger.ch

www.karger.com (c) 2012 S. Karger AG, Basel

0025-7931/12/0841-0075\$38.00/0

Accessible online at:

www.karger.com/res
Shane Hanon

Consultatie Pneumologie, UZ Brussel

Laarbeeklaan 101

BE-1090 Brussels (Belgium)

Tel. +32 247634 53, E-Mail shane.hanon@ uzbrussel.be 


\section{Introduction}

Diffuse panbronchiolitis (DPB) is an inflammatory disease of the peripheral airways that almost exclusively affects patients of East Asian descent. Clinical symptoms appear in the 2nd to 5th decade and typically consist of productive cough and dyspnea on exertion. A vast majority of patients also have chronic sinusitis $[1,2]$.

If left untreated, the disease progresses with worsening airways obstruction, the development of bronchiectasis, repeated infections and cor pulmonale, which eventually cause respiratory failure and death [2]. Macrolide antibiotics (e.g. azithromycin) are the recommended treatment for DPB, although high-quality evidence for their use is lacking [3]. Upon pathological examination, a distinct feature of DPB is prominent inflammation of the respiratory bronchioles, while the alveoli remain mostly unaffected $[1,2]$. Baseline pulmonary function is essentially characterized by an obstructive pattern, often combined with air trapping. Reduced end-expiratory flows and reduced diffusing capacity have also been reported $[1,2,4]$. The sparse studies on lung function changes under macrolide treatment in DPB have methodological limitations and mostly report overall lung function parameters such as $\mathrm{FEV}_{1}$ and FVC. Changes in small airways function are also sometimes assessed, based on RV/TLC or end-expiratory flow rates $[1,4]$.

Because DPB is mainly a disease of the small airways, we monitored treatment in our patient with lung function testing that included a specific, noninvasive test of small airways function, i.e. the multiple breath nitrogen washout (MBW). Phase III slope analysis of MBW yields the indices $S_{\text {cond }}$ and $S_{\text {acin }}$ that assess ventilation heterogeneity at the level of the conductive airways (where ventilation distribution is governed by convection) and the acinar airways (where ventilation distribution is determined by diffusion-convection interaction), respectively. Peripheral lung disease has been characterized by increased $S_{\text {cond }}$ and $S_{\text {acin }}$ values, and also by an increased lung clearance index (LCI) which is nonspecific to any anatomical location [5].

\section{Case Report}

A 67-year-old nonsmoking Chinese immigrant presented with a long-standing productive cough, dyspnea on exertion and nasal obstruction due to extensive sinonasal polyposis.
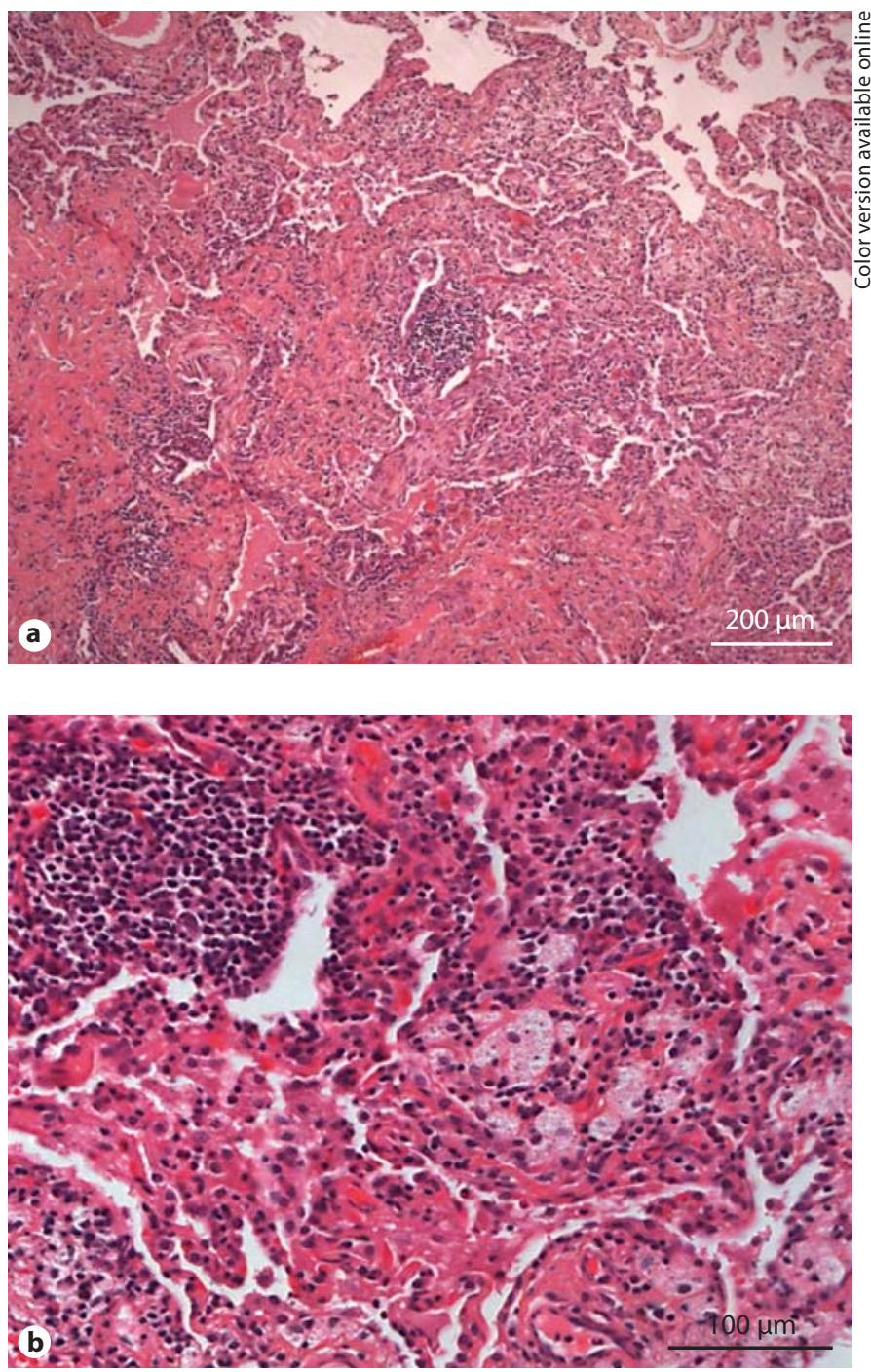

Fig. 1. Lung biopsy. a Chronic bronchiolitis characterized by a dense peribronchiolar infiltrate of lymphocytes and plasma cells. Neutrophils are observed in the lumen of bronchioles. b Around some bronchioles, aggregates of foamy macrophages are seen. Lesions of follicular bronchiolitis are also present.

The chest CT scan revealed diffuse centrilobular micronodular opacities and global thickening of airway walls as well as mild bronchiolectasis.

The clinical diagnosis of DPB was confirmed by surgical lung biopsy (fig. 1).

Lung function data obtained at the baseline visit, and data averaged over months 6-16 are shown in table 1 . For selected parameters, the monthly evolutions are shown in figures 2 and 3. Baseline spirometry was also obtained after bronchodilation, showing a small degree of reversibility : $\mathrm{FEV}_{1}=63 \%$ predicted and $\mathrm{FEV}_{1} / \mathrm{FVC}=66 \%$, both postbronchodilation. At baseline, air trapping was observed $(\mathrm{RV} / \mathrm{TLC}=57 \% ; 143 \%$ predicted $)$ and a 

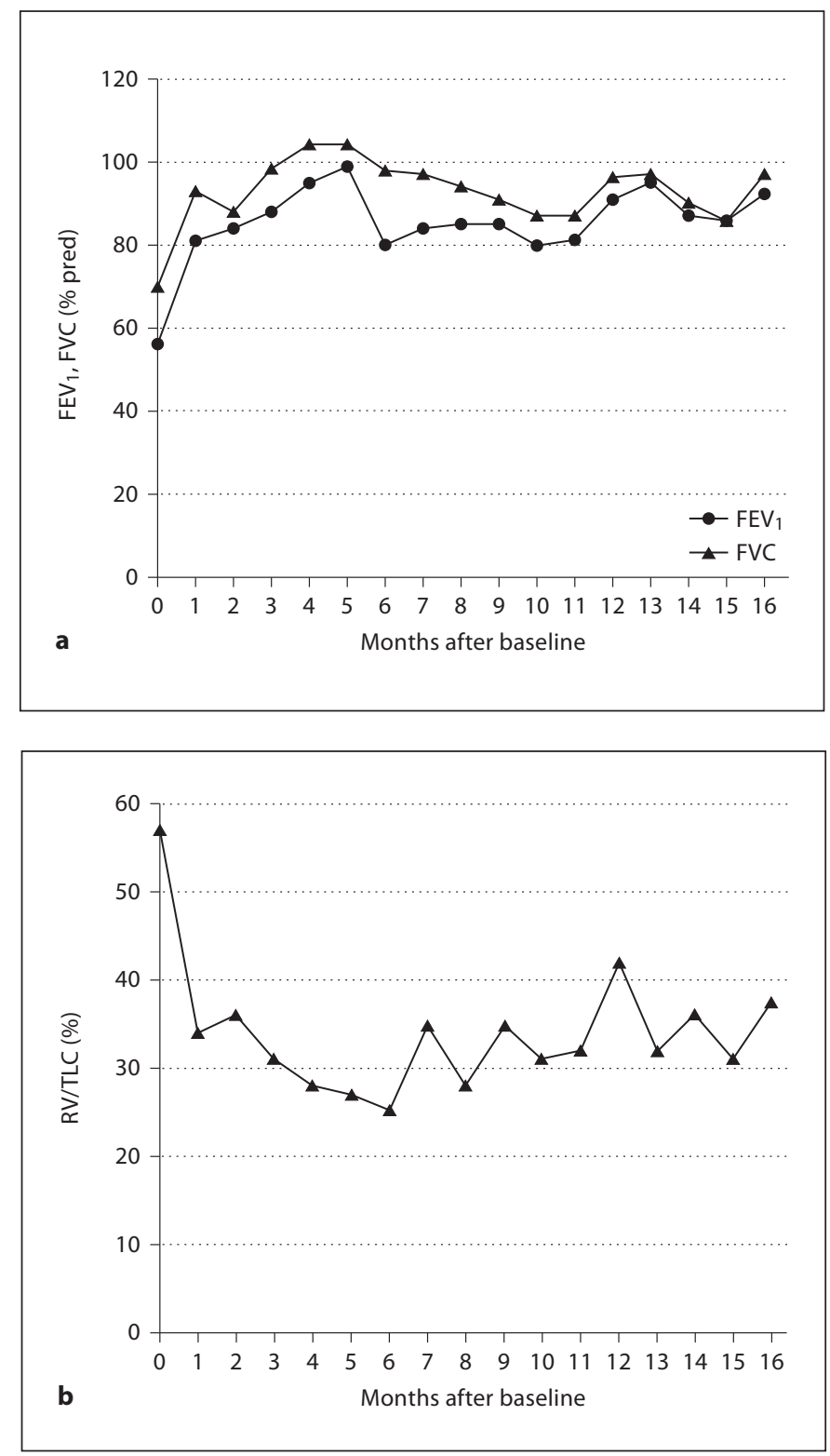

Fig. 2. a $\mathrm{FEV}_{1}$ and $\mathrm{FVC}$ (\% predicted) versus the months after baseline. b RV/TLC (\%) versus the months after baseline.

markedly reduced diffusing capacity $\left(\mathrm{TL}_{\mathrm{CO}}=48 \%\right.$ predicted; corrected for hemoglobin), with normal $\mathrm{K}_{\mathrm{CO}}$ (97\% predicted). Forced end-expiratory flow rates were very low $\left(\mathrm{FEF}_{75}=23 \%\right.$ predicted). Both $\mathrm{S}_{\text {cond }}\left(0.111 /\right.$ liter) and $\mathrm{S}_{\text {acin }}(0.61 /$ liter), as well as LCI (12.0) were well outside their normal range. While predicted values for standard lung function tests derive from an established reference [6], the predicted normal $S_{\text {acin }}, S_{\text {cond }}$ and LCI values and upper limits of normal (see footnote in table 1) are based on a local cohort of 120 never-smokers (50\% male) evenly distributed across the age range $25-65$ years; equations were extrapolated to 67 years [7].
Table 1. Lung function parameters at baseline and averaged over months 6-16

\begin{tabular}{|c|c|c|}
\hline & Baseline & $\begin{array}{l}6-16 \text { months } \\
\text { average } \pm S D\end{array}$ \\
\hline \multicolumn{3}{|l|}{ Spirometry } \\
\hline $\mathrm{FEV}_{1}, \%$ pred & 56 & $86 \pm 5$ \\
\hline $\mathrm{FEV}_{1}$, liters & 1.67 & $2.57 \pm 0.15$ \\
\hline FVC, \% pred & 70 & $93 \pm 5$ \\
\hline FVC, liters & 2.72 & $3.57 \pm 0.18$ \\
\hline $\mathrm{FEV}_{1} / \mathrm{FVC}, \%$ & 61 & $72 \pm 4$ \\
\hline $\mathrm{FEF}_{75}, \%$ pred & 23 & $35 \pm 11$ \\
\hline \multicolumn{3}{|l|}{ Lung volumes } \\
\hline RV/TLC, \% & 57 & $33 \pm 5$ \\
\hline RV/TLC, \% pred & 143 & $83 \pm 11$ \\
\hline $\mathrm{RV}$, liters & 3.63 & $1.83 \pm 0.41$ \\
\hline RV, \% pred & 145 & $72 \pm 16$ \\
\hline TLC, liters & 6.35 & $5.46 \pm 0.43$ \\
\hline TLC, \% pred & 94 & $81 \pm 6$ \\
\hline \multicolumn{3}{|l|}{ Diffusing capacity } \\
\hline $\mathrm{D}_{\mathrm{LCO}}, \%$ pred & 48 & $52 \pm 3$ \\
\hline $\mathrm{K}_{\mathrm{CO}}, \%$ pred & 97 & $86 \pm 4$ \\
\hline \multicolumn{3}{|l|}{ MBW indices } \\
\hline LCI & 12.0 & $7.1 \pm 0.3$ \\
\hline $\mathrm{S}_{\text {acin }}, \mathrm{L}^{-1}$ & 0.61 & $0.23 \pm 0.04$ \\
\hline $\mathrm{S}_{\text {cond }}, \mathrm{L}^{-1}$ & 0.111 & $0.044 \pm 0.012$ \\
\hline
\end{tabular}

For a 67-year-old never-smoker male: predicted values are $\mathrm{S}_{\text {acin }}\left(0.13 /\right.$ liter), $\mathrm{S}_{\text {cond }}(0.043 /$ liter $)$ and LCI $[6,8]$.

Upper limit of normal (1.645 SD) values are $S_{\text {acin }}(0.18 /$ liter), $\mathrm{S}_{\text {cond }}(0.062 /$ liter $)$ and LCI $[7,3]$.

Predicted values for spirometry, lung volumes and diffusing capacity are based on [6]. pred $=$ Predicted .

Low-dose long-term macrolide antibiotic treatment, i.e. 250 mg azithromycin twice weekly, was started, and a monthly ambulatory clinical follow-up with detailed lung function testing (spirometry, lung volumes, diffusing capacity and MBW) was performed.

There was a spectacular improvement in symptoms within 1 month after starting azithromycin, with an almost complete disappearance of cough and dyspnea on exertion.

Lung function tests showed rapid improvements of $\mathrm{FEV}_{1}, \mathrm{FVC}$ (fig. 2a) and RV/TLC (fig. 2b) within 1 month, which persisted throughout the observation period (table 1). By contrast, $\mathrm{FEF}_{75}$ and $\mathrm{TL}_{\mathrm{CO}}$ did not show any consistent trend. Striking improvements were observed in both MBW indices: $S_{\text {cond }}$ progressively improved to within a normal range (fig. 3 a; table 1 ), while $S_{\text {acin }}$, although improved, remained well above the upper limit of normal (fig. 3b; table 1). After a rapid initial decrease to 8.6 after 1 month, LCI further dropped to 6.8 by month 5 , and remained stable and close to the upper limit of normal for the remainder of the follow-up period (table 1). 

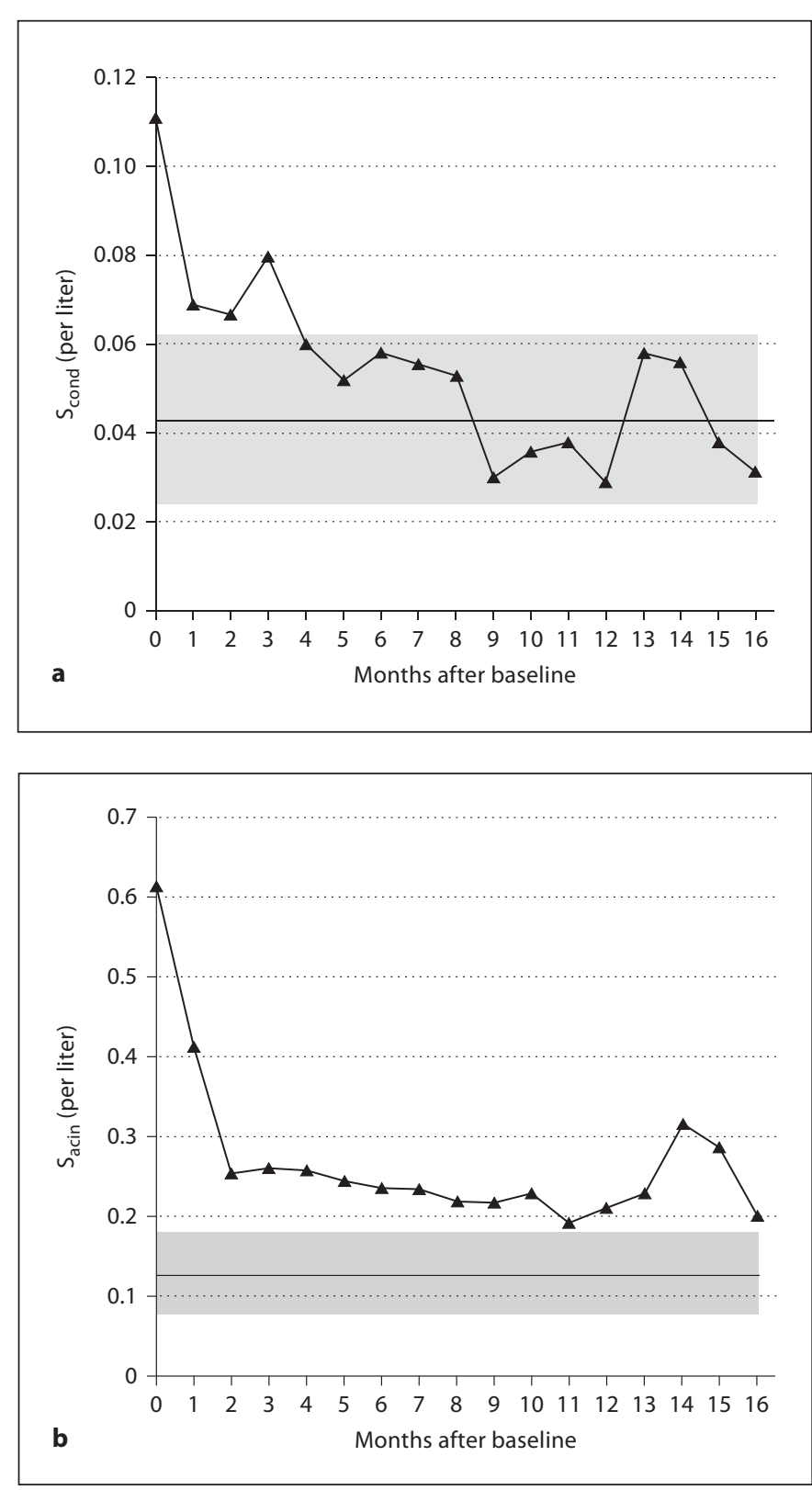

Fig. 3. a $S_{\text {cond }}$ versus the months after baseline. The solid line indicates the predicted value and the grey shaded area delimits the zone of normality, i.e. the upper and lower limits of normal. $\mathbf{b} \mathrm{S}_{\text {acin }}$ versus the months after baseline (same representation as in $\mathbf{a}$ ).

\section{Discussion}

A 250-milligram dose of azithromycin twice weekly was effective in treating DPB in this patient, both in terms of symptoms and lung function including small airways ventilation heterogeneity.
The rapid and sustained improvements observed for $\mathrm{FEV}_{1}$, FVC and RV/TLC are consistent with existing literature data on DPB under macrolide treatment $[1,4]$.

It has also been suggested that small airways function can improve under macrolide therapy based on reductions in the RV/TLC ratio $[1,4]$. In a series of 24 cases [4], end-expiratory flow rates did not significantly improve; a finding which is in accordance with the unchanged $\mathrm{FEF}_{75}$ in our patient. However in this case, where marked FVC changes are observed, any changes or absence of change in $\mathrm{FEF}_{75}$ are difficult to interpret.

While pathological findings of inflammation of the respiratory bronchioles are expected to entail small airways dysfunction, the MBW enabled us to actually measure it. The degree of $S_{\text {cond }}$ and $S_{\text {acin }}$ abnormality at baseline was, in fact, very similar to that previously obtained in lung-transplant patients suffering from bronchiolitis obliterans [8]; in these patients, average $S_{\text {acin }}$ and $S_{\text {cond }}$ values were roughly $0.5 /$ liter and $0.09 /$ liter. The similar degree of $S_{\text {cond }}$ and $S_{\text {acin }}$ abnormality to that observed here is probably not a coincidence, given the histopathological similarities between both diseases, specifically involving the respiratory bronchioles.

It has recently been suggested, on the basis of relationships between LCI, $S_{\text {acin }}$ and $S_{\text {cond }}$ in asthma [5], that in the case of airway constriction in small airways around the acinar entrance, this may translate into elevated $S_{\text {cond }}$ (for small airways proximal to acinar entrance) and elevated $S_{\text {acin }}$ (for small airways distal to acinar entrance). Strictly speaking, the normal $S_{\text {cond }}$ value after 5 months could reflect a therapeutic effect of azithromycin on conductive airways of all sizes. However, the striking and parallel improvements of both $S_{\text {cond }}$ and $S_{\text {acin }}$ (and also LCI) under azithromycin suggest that the functional improvement represented in $S_{\text {cond }}$ is at least in part obtained in the small airways proximal to the acinar entrance.

After showing a rapid improvement, $S_{\text {acin }}$ stayed well above its normal range throughout the follow-up period, suggesting a distinct structural abnormality in the acinar lung zone that cannot be fully reversed by macrolide antibiotic therapy in DPB. The remaining ventilation heterogeneity within the acinar lung zone could also be partly responsible for an underestimation of diffusing capacity. Finally, we need to bear in mind that for this patient of Chinese ethnicity, predicted values for standard lung function parameters (derived from a West European population) [6] and from our local database [7] may not be strictly valid, making the assessment of true abnormality difficult in this case. Nevertheless, follow-up scenarios such as the one presented here can at least quan- 
tify the degree of improvement that can be obtained with macrolide treatment in DPB. To conclude, the most distinct functional improvements in this DPB patient were seen on those indices of lung function, including MBW, that are known to be particularly sensitive to small airway changes.

\section{Acknowledgements}

We thank Dr. Bart Ilsen for interpreting the chest CT scans and Dr. Caroline Geers for examining the lung biopsy specimens.

\section{References}

1 Azuma A, Kudoh S: Diffuse panbronchiolitis in East Asia. Respirology 2006;11:249-261.

2 Poletti V, Casoni G, Chilosi M, Zompatori M: Diffuse panbronchiolitis. Eur Respir J 2006;28:862-871.

3 Yang $\mathrm{M}$, Dong BR, Lu J, Lin X, Wu HM: Macrolides for diffuse panbronchiolitis. Cochrane Database Syst Rev 2010;12: CD007716.

4 Yamada G, Igarashi T, Itoh E, Tanaka H, Sekine K, Shosaku A: Centrilobular nodules correlate with air trapping in diffuse panbronchiolitis during erythromycin therapy. Chest 2001;120:198-202.

5 Verbanck SA, Paiva M, Schuermans D, Hanon S, Vincken W, Van Muylem A: Relationships between the lung clearance index and conductive and acinar ventilation heterogeneity. J Appl Physiol 2012 Mar;112:782-790.

-6 Quanjer PH, Tammeling GJ, Cotes JE, et al: Lung volumes and forced ventilatory flows. Working Party Report of the Standardiza- tion of Lung Function Tests, European Community for Steel and Coal. Official Statement of the European Respiratory Society. Eur Respir J Suppl 1993;16:5-40.

7 Verbanck S, Thompson BR, Schuermans D, et al: Ventilation heterogeneity in the acinar and conductive zones of the normal ageing lung. Thorax 2012, Apr 27, E-pub ahead of print.

8 Van Muylem A, Verbanck S, Estenne M: Monitoring the lung periphery of transplanted lungs. Respir Physiol Neurobiol 2005;148:141-151. 